\title{
Vaccine Preventable Diseases in Children Following a Nationwide Sanitation Campaign
}

Parvati Singh ( $\sim$ parvatis@uci.edu )

University of California Irvine https://orcid.org/0000-0002-3800-2808

Donald N. Forthal

UCl: University of California Irvine

Manisha Shah

UCLA: University of California Los Angeles

Tim A. Bruckner

UCl: University of California Irvine

Research article

Keywords: Vaccine Preventable Diseases (VPDs), under 5-year children, India, toilets, open defecation, Swachh Bharat Mission

Posted Date: December 1st, 2020

DOI: https://doi.org/10.21203/rs.3.rs-115154/v1

License: (1) (1) This work is licensed under a Creative Commons Attribution 4.0 International License.

Read Full License 
Title: Vaccine preventable diseases in children following a nationwide sanitation campaign

\author{
Parvati Singh, $\mathrm{PhD}^{\mathrm{a}}$ \\ Donald N. Forthal, MD \\ Manisha Shah, $\mathrm{PhD}^{\mathrm{c}}$ \\ Tim A. Bruckner, $\mathrm{PhD}^{\mathrm{d}}$
}

Author affiliations:

${ }^{\text {a }}$ Postdoctoral Researcher, Program in Public Health ,Anteater Instruction \& Research Offices

(AIRB), 653 E. Peltason Dr., 2nd Floor, University of California, Irvine, Irvine, CA, 92697-3957

USA. Email: parvatis@uci.edu

${ }^{\mathrm{b}}$ Professor of Medicine and Molecular Biology and Biochemistry, Center for Virus Research, Chief, Division of Infectious Diseases, 3044 Hewitt Hall, University of California, Irvine, School of Medicine, Irvine, CA 92617 Email: dnfortha@hs.uci.edu

${ }^{c}$ Vice-Chair \& Professor, Department of Public Policy, Luskin School of Public Affairs, University of California, Los Angeles, 3250 Public Affairs Building - Box 951656, Los Angeles, CA 90095-1656. Email: manishashah@ucla.edu

${ }^{\mathrm{d}}$ Associate Professor of Public Health, Program in Public Health, Anteater Instruction\& Research Offices (AIRB), 653 E. Peltason Dr., 2nd Floor, University of California, Irvine, Irvine, CA, 92697-3957 USA. Email: tim.bruckner@uci.edu

\title{
Corresponding Author:
}

Parvati Singh, Postdoctoral Researcher, Program in Public Health, Anteater Instruction\& Research Offices (AIRB), 653 E. Peltason Dr., 2nd Floor, University of California, Irvine, Irvine, CA, 92697-3957 USA. Email: parvatis@ uci.edu 


\section{$\underline{\text { Declarations }}$}

Ethics approval and consent to participate: Not applicable. This study used publicly available secondary data and was IRB exempt.

Consent to publish: Not applicable.

Availability of data and materials: The datasets underlying this article are available from the following sources in the public domain:

1. Health Management Information System (HMIS) India: Health Management Information System: A digital initiative under National Health Mission. Ministry of Health \& Family Welfare, Government of India. 2020. Available from: https://nrhmmis.nic.in/hmisreports/frmstandard_reports.aspx

2. Annual Health Survey (second round): Annual Health Survey (AHS) India. Office of the Registrar General and Census Commissioner (India) 2014. URL: http://www.censusindia.gov.in/2011census/hh-series/cab.html

3. District Level Household and Facility Survey (DLHS-4), 2012-13. IIPS, International Institute of Population Sciences, Mumbai, India. Deonar, Mumbai, 2014. URL: http://www.nrhmmis.nic.in/SitePages/DLHS-4.aspx

4. National Family Health Survey (NFHS-4): International Institute for Population Sciences (IIPS) and ICF. National Family Health Survey (NFHS-4), 2015-16: India. Mumbai: IIPS 2017. URL: https://dhsprogram.com/pubs/pdf/FR339/FR339.pdf

Competing Interests: The Authors declare no competing interests.

Funding: Funding for this research was provided by the National Institute of Allergy and Infectious Diseases: 1R03AI135322-01.

Role of the funding source: The funding source had to involvement in in study design; in the collection, analysis and interpretation of data; in the writing of the report; and in the decision to submit the article for publication.

Authors' contributions: PS: Conceptualization; Data curation; Formal analysis; Funding acquisition; Investigation; Methodology; Project administration; Resources; Software; Supervision; Validation; Visualization; Roles/Writing - original draft; Writing - review \& editing. DNF: Conceptualization; Investigation; Supervision; Validation; Roles/Writing original draft; Writing - review \& editing. MS: Formal analysis; Investigation; Methodology; Supervision; Validation; Roles/Writing - original draft; Writing - review \& editing. TAB: Conceptualization; Data curation; Formal analysis; Funding acquisition; Investigation; Methodology; Project administration; Resources; Software; Supervision; Validation; Visualization; Roles/Writing - original draft; Writing - review \& editing.

Acknowledgements: Not Applicable

\section{Abbreviations:}

SBM: Swachh Bharat Mission; u5: under 5 years old; VPD: Vaccine Preventable Diseases; DPT: Diphtheria Pertussis Tetanus; HMIS: Health Management Information System; AHS: Annual Health Survey; DLSH: District Level Household and Facility Survey; NFHS: National Family Health Survey. 


\begin{abstract}
Background: India consistently reports the most diphtheria, pertussis, tetanus and measles cases worldwide. Persistent exposure to fecal pathogens due to open defecation may cause environmental enteropathy that in may lead to undernutrition and vaccine failure in under 5-year old (u5) children. The Swachh Bharat Mission (SBM) program in India, launched in 2014, aimed to construct toilets for every household nationwide and reduce open defecation.

Objective: We examine whether increased household toilet availability in Indian districts corresponds with a reduction in 4 Vaccine Preventable Diseases (VPDs): diphtheria, pertussis, tetanus and measles.

Methods: We retrieved data on district level change in the prevalence (per 1000 u5 children) of 4 VPDs, from 2013 (pre-SBM) to 2016 (post-SBM). We obtained data on our exposure, the change in the percentage of households with toilets (per district), from three large national surveys conducted in 2013 and 2016. We used linear regression analysis which controlled for change over time in socioeconomic factors, health system-related covariates and pre-SBM prevalence of VPDs.

Results: A one percentage point increase in households with toilets corresponds with 0.33 fewer measles cases per $1000 \mathrm{u} 5$ children in that district (coefficient: $-0.33,95 \%$ CI: -0.0641, -0.014; p $<0.05)$. We observe no relation with diphtheria, pertussis, or tetanus.

Conclusion: Rapid improvements in ambient sanitation through increased toilet availability (and reduction in open defecation) may correspond with reduction in the prevalence of measles in u5 children.
\end{abstract}

Key words: Vaccine Preventable Diseases (VPDs); under 5-year children; India, toilets; open defecation; Swachh Bharat Mission 


\section{Background}

In 2019, India recorded the greatest incidence of diphtheria and tetanus of any country worldwide.(1) India also ranked among the top 10 countries worldwide in pertussis and measles cases.(1) Whereas overall cases for these vaccine preventable diseases (VPDs) declined steadily over the past decade, India's abysmal global ranking raises questions about low vaccine effectiveness despite its over $90 \%$ immunization coverage following the initiation of the Universal Immunization Program in 2012.(2) Current immunization programs may require augmentation through separate public health measures that reduce the prevalence of infectious diseases and/or strengthen immune response to vaccines particularly in under 5-year old (u5) children who bear the greatest burden of these illnesses.(3)

Improved sanitation may play a role in strengthening children's immune response.(4) Owing to lack of toilets and the widespread practice of open defecation, India serves as a unique case study for examining the role of improved sanitation on vaccine efficacy and VPD reduction in u5 children.(5,6) As of 2015, over $60 \%$ of the global population that practices open defecation lives in India. $(5,6)$ This practice exposes populations to fecal pathogens and imposes a significant negative externality. The prevalence of open defecation in a neighborhood (i.e., sanitation behavior of others in the immediate surroundings) is an ecological exposure that adversely affects child health. $(7,8)$

Prolonged exposure to fecal pathogens may cause environmental enteropathy, also referred to as tropical enteropathy or jejunitis.(9) This condition, or syndrome, includes nutrient malabsorption in the small intestine, atrophy of intestinal villi, crypt hyperplasia, T-cell infiltration and inflammation of the jejunum.(4,9) Environmental enteropathy may cause undernutrition that, in turn, may lead to immune dysfunction and impairment.(4) Researchers assert that levels of 
antibodies produced after vaccination are lower among malnourished children and that environmental enteropathy contributes to this phenomenon.(10) Moreover, environmental enteropathy can lead to induction of regulatory $\mathrm{T}$ cells which can diminish vaccine-specific responses, or destroy an attenuated vaccine by an aggressive local immune response in the digestive tract. $(11,12)$

Whereas environmental enteropathy is better characterized with respect to oral vaccine responses(11,12) (e.g., polio and rotavirus), although with mixed evidence $(13,14)$, studies also find an association between enteropathy and diminished parenteral vaccine response through suppressed immunity, altered gut microbiota and undernutrition.(15-17) For instance, research finds lower measles-specific IgG antibody levels in undernourished infants, with higher susceptibility to measles infection despite vaccination.(18) Large sample multi-national analyses also report a positive association between deaths due to measles and undernutrition in children.(19) Environmental exposures and nutrition status may also moderate humoral response to pertussis vaccine.(20) Vaccine responses to diphtheria and tetanus appear attenuated in severely undernourished children but not among those with mild-to-moderate undernutrition.(10)

Encouragingly, rapid improvements in ambient sanitation may reverse environmental enteropathy within a relatively short time span.(21,22) Public health investments in improving sanitation and reducing open defecation, therefore, may serve as a key strategy towards augmenting universal immunization efforts and reducing the burden of VPDs. In October 2014, the Indian federal government launched one of the world's biggest national sanitation programsthe Swachh Bharat Mission (SBM). SBM aims to construct toilets for every Indian household and eliminate the practice of open defecation by 2019.(23) Over this five year period, the SBM program received annual funding of over $\$ 1$ billion. According to government statistics, over 100 
million toilets have been constructed across the country thus far.(23) This program combined financial incentives for toilet construction (at the household level) with intensive behavioral change messaging through multiple channels (community mobilization, social media, radio, television, public service announcements and cinema) that promoted toilet utilization and sanitary behaviors. Between late 2014 and early 2019, the Indian population was exposed to about 2,5003,300 SBM-related messages per capita, amounting to, on average, 11 sanitation-related behavior change messages per person per week (Dalberg WASH Institute, 2019).(24) Whereas India has implemented other sanitation policies in the decades preceding SBM, none of the prior programs combined public awareness campaigns with toilet construction on the scale of SBM.(25)

Recent work suggests that increased toilet availability following the SBM program may have reduced child undernutrition(26) and diarrheal outbreaks(27) in India. However, we know of no work that examines whether these improvements extend to reduced VPD prevalence among u5 Indian children. We leverage the quasi-random nature of the SBM program to examine whether large increases in toilet availability correspond with reductions in each of four VPDs in u5 children- diphtheria, pertussis, tetanus and measles. We examine 532 districts in India and analyze whether a change in household-level toilet availability, pre- and post-SBM (2013 and 2016 respectively) varies inversely with VPD prevalence over time. Our district-level ecological analysis, conducted for almost all Indian states, may hold key implications for public health and policy with respect to understanding whether sanitation improvements have the potential to reduce the high burden of child mortality from VPDs. 


\section{Methods}

Data and variables

Starting in 2012, the Government of India's National Health Mission publishes annual district level data on the prevalence of VPDs among u5 children through a Health Management Information System (HMIS) portal.(28) While its relative novelty has precluded it from wide use, recent literature acknowledges the superiority of HMIS data over previously existing databases on immunization and VPDs in India. $(29,30)$ The HMIS reports annual district-level information on immunization, adverse events and prevalence of diphtheria, pertussis, tetanus, measles and other illnesses among u5 children.(28) These data serve as a central repository of VPD surveillance across India and undergo several rounds of validation checks at village, sub-center, block, district and state-levels.(31) HMIS data files are publicly available.(28) We used these data to retrieve information on our outcomes of interest: the change in prevalence of (a) diphtheria (b) pertussis (c) tetanus and (d) measles per 1000 under-5 year old (u5) children, per district, from 2013 (preSBM) to 2016 (post-SBM), for all Indian districts.

We retrieved data on our exposure (district-level change from 2013 to 2016 in percentage of households with toilets) from three national survey datasets. These three datasets comprise (a) District Level Household \& Facility Survey, round 4 (DLHS-4), (b) Annual Health Survey (AHS, second update) and (c) National Family Health Survey, round 4 (NFHS-4). DLHS 4 is a nationwide survey sponsored by the Ministry of Health and Family Welfare and covers 21 states and union territories (321 districts) with 1000 to 1500 households sampled under each district.(32) AHS is sponsored by the Office of the Registrar General, India, on behalf of the Ministry of Health \& Family Welfare for 9 high-risk states that have traditionally fared the worst in terms of child health indicators in India.(33) AHS covers 284 districts with an average of 12,000 households sampled 
per district.(33) The DLHS-4 and AHS datasets report information for 2013 (pre-SBM). The National Family Health survey is a decennial survey in India administered through the Demographic Health Surveys Program and its fourth round (NFHS-4) reports data for 2016 (postSBM).(34) Its sample size is approximately 572,000 households, in 640 districts across all 29 states and 9 union territories in India.(34) NFHS-4, unlike its predecessor (NFHS-3), contains substate geographic identifiers, permitting the use of districts as the unit of analysis.(34) Households surveyed in DLHS-4, AHS and NFHS-4 are sampled to be representative (in aggregate) at the district level and have been utilized extensively in pooled longitudinal format.(35,36) According to an analysis by the World Health Organization, these datasets have been used in over 600 scientific publications, in addition to extensive utilization by the World Bank, Government of India and other policy making agencies.(37)

HMIS data report the relative percentage of VPDs to total reported childhood diseases (per district, per year). We converted these ratios to absolute prevalence (per 1000 u5 children per district-year) using the number of u 5 children reporting any illness from AHS, DLHS-4 and NFHS4. Using these survey datasets, we also calculated the number of households reporting use of unshared (i.e., personal) toilets as a percentage of total number of surveyed households per district in 2013 and 2016. We defined our exposure as the difference in district-level percentage of households with toilets in 2016 relative to 2013 . We also obtained a set of control variables from the DLHS-4, AHS and NFHS-4 datasets to account for factors that may have changed from 2013 to 2016 and that might be associated with changes in VPD prevalence. These variables include change in percentage of households with electricity, percentage of households with clean drinking water (boiled and/or treated), percentage of households with clean cooking fuel (liquefied petroleum gas and/or biogas), percentage of women with $10^{\text {th }}$ grade or higher education, 
percentage of child births in hospitals (institutional deliveries), percentage of $\leq 1$ year old children who received diphtheria-pertussis-tetanus (DPT) vaccine and percentage of $\leq 1$ year-old children who received the measles vaccine. A large literature describes the role of these variables in determining child health outcomes in developing countries.(38) Their inclusion reduces confounding by general improvements in district-level health systems and socioeconomic attributes that may co-occur with implementation of the SBM program over the study period. Our final analytic file containing districts reported uniformly across all datasets (HMIS, DLHS-4/AHS, NFHS-4) comprised 532 districts as the units of analysis. Gujarat, Jammu \& Kashmir and a few Union Territories were excluded as they were not covered in the pre-SBM survey datasets (AHS, DLHS-4)

Analysis

We specified the following test equation:

$\Delta \mathrm{Y}=\beta_{0}+\beta_{1} \Delta$ Percentage of households with toilets $+\beta_{2}$ Baseline VPD prevalence +

$\boldsymbol{\beta}^{\prime} \Delta$ Controls $+\varepsilon$

-Equation 1

where

$\Delta \mathrm{Y}$ is the change in VPD prevalence (2016 minus 2013) per $1000 \mathrm{u} 5$ children per district, examined separately by VPD type (Diphtheria, Pertussis, Tetanus, Measles)

$\Delta$ Percentage of households with toilets is the change in percentage of households with toilets (2016 minus 2013) per district. $\beta_{1}$ serves as the main coefficient of interest.

Baseline VPD prevalence is the pre-SBM (i.e., 2013) prevalence of respective VPD per $1000 \mathrm{u} 5$ children. 
$\Delta$ Controls is the vector of control variables (2016 minus 2013) listed earlier.

$\varepsilon$ is the heteroscedasticity-robust standard error term.

We utilized Ordinary Least Squares (OLS) regression analysis to estimate Equation 1 separately for each VPD. For tests that rejected the null, we stratified Equation 1 by India's administrative regions (central, eastern, northern, north eastern, southern and western) to explore which regions show the greatest change in outcome per increase in exposure. In addition, for any results in which rejected the null, we then reformulated the outcome as change in counts (as opposed to per 1000 prevalence) of VPDs in u5 children per district to obtain the average marginal effect of change in exposure on the outcome (case counts). For all analyses, we specified robust standard errors to account for correlated errors. We conducted all analyses in Stata SE version 14.2.(39)

\section{Results}

Table 1 describes the mean and standard deviation of the covariates included in our study by pre- and post-SBM, as well as the change over this period. The prevalence of VPDs in u5 children (per 1000) declines from 2013 to 2016. Measles shows the greatest reduction, followed by diphtheria, pertussis and tetanus. These trends align with India's national surveillance data reported by the World Health Organization.(40) Mean percentage of households with toilets per district increases from $45 \%$ in 2013 to $53 \%$ in 2016, which agrees with other reports.(41) Appendix Table 1 describes the distribution of outcome variables (mean) at various percentiles. Most districts (from the $25^{\text {th }}$ to $95^{\text {th }}$ percentile) report no change from 2013 to 2016 in diphtheria, pertussis and tetanus, except at the lowest $\left(1^{\text {st }}\right.$ to $\left.10^{\text {th }}\right)$ and highest $\left(95^{\text {th }}\right.$ to $\left.99^{\text {th }}\right)$ percentiles of 
change. The distribution of change in prevalence of measles (per 1000 u5 children) over time is relatively more uniform across all percentiles of change.

Figure 1 maps the district-level change in VPDs (2016 minus 2013) across India. Sections of Gujarat, Jammu \& Kashmir, Bihar, Maharashtra, Madhya Pradesh and Telangana show reduction in diphtheria (Figure 1, Panel A). Prevalence of pertussis does not change in most regions, except for some areas in Rajasthan, Bihar, Kerala and a few other districts (Figure 1, Panel B). Tetanus in u5 children declines in some parts of northern and central India, with most regions showing no change (Figure 1, Panel C). The prevalence of measles shows substantial decline across almost all Indian states (except Rajasthan and Maharashtra), with Madhya Pradesh, Chhattisgarh, Bihar, Odisha and Karnataka showing near-universal decline in all districts within these states.

Figure 2 maps the change in district-level percentage of households with toilets across India. We observe a near-uniform increase in household-level toilet availability nation-wide. The most visible improvements occur in Rajasthan, Himachal Pradesh, Chhattisgarh, Assam and Odisha.

We observe no relation between increase in percentage of households with toilets and change in the prevalence of Diphtheria, Pertussis and Tetanus per 1000 u5 children (Table 2, Models 1, 2, 3). However, for every one percent increase in exposure, the prevalence of measles in u5 children (per 1000) declines by 0.33 units (coefficient $=-0.33,95 \%$ CI: $-0.641,-0.014, p<$ 0.05) (Table 2, Model 4). This decline concentrates in central and north eastern Indian districts (Appendix Table A.2), presumably owing to greater change in percentage of households with toilets in these two regions (Appendix Table A.3). Examination of change in counts (rather than prevalence per 1000 u5 children) of u5 measles cases indicates 0.16 fewer cases for every one 
percentage point increase in exposure. Put another way, for a $7 \%$ increase in households with toilets (i.e., mean change reported in Table 1), our analyses suggest 1.12 fewer cases of measles in u5 children per district, on average, over our study period (Appendix Figure A.1).

\section{Discussion}

Open defecation exposes populations to fecal matter pathogens and may cause environmental enteropathy. This enteropathy may interfere with immune functioning and vaccine response in children.(4,9) India reports the greatest prevalence globally of open defecation stemming from lack of toilet availability and usage.(6) The Swachh Bharat Mission (SBM) program, launched in 2014 by the Government of India, aimed to eliminate open defecation through intensive behavioral change messaging and construction of over 100 million toilets nationwide.(23) We examined whether and to what extent increase in toilet availability varied inversely with four Vaccine Preventable Diseases, namely, diphtheria, pertussis, tetanus and measles, in u5 children. We find that an increase in percentage of households with toilets is associated with a modest reduction in measles, but not in diphtheria, pertussis or tetanus. Findings provide proof-of-concept that improvements in ambient sanitation may augment universal immunization efforts in reducing the burden of measles among u5 children in India.

Strengths of this study include the utilization of precise timing of an exogenously determined public sanitation program (SBM), which lends a quasi-experimental design to our analysis. We also view the brief time lag post-SBM initiation as a strength of the study design. Use of a shorter time lag minimizes the risk of confounding due to the plausible rival of "maturation" in which a variety of infrastructure improvements, and cultural changes, which 
follow SBM but are not caused by SBM, improve child health overall. Maturation, for instance, would tend to threaten validity had we extended the time-horizon to several years postintervention.(42)

In addition, we use large, nationally representative data sources that permit analysis of VPDs in u5 children with respect to open defecation - a district-level exposure that carries a high negative externality. Furthermore, all datasets used in this study are publicly available which permits replication. We also minimize confounding by specifying in our analysis several key variables that are widely recognized as strong correlates of child health outcomes. Lastly, we account for baseline differences across districts in the prevalence of VPDs, which reduces the threat of regression to the mean over the study period.

One limitations of our study is that we do not examine the relation between VPD and toilets by rural or urban regions. Prior research reports that child health may vary by population density of open defecation and by toilet availability within districts. $(7,43)$ The HMIS data, however, do not report VPD prevalence by rural/urban divisions within districts and hence limit detailed analyses by within-district regions. Owing to data limitations, we also cannot examine differential responses by gender or age groups.(26) Whereas current HMIS data remain limited to aggregate district-level reporting, we encourage future research to extend our analyses and examine these subgroups following availability of detailed VPD surveillance datasets in India.

Our analyses indicate a decline in prevalence of measles in u5 children following increased toilet availability, but no changes in the prevalence of diphtheria, pertussis and tetanus. We offer three post hoc explanations for this observation. First, vaccine response to measles relies on vitamin A supplementation and absorption.(44) Vitamin A supplementation increased from 54\% in 2013 to $71 \%$ in 2016 among u5 children in India.(45) This increase, combined with increased 
toilet availability (and potential reduction in environmental enteropathy) in some districts may correspond with improved absorption of Vitamin A in u5 children. Second, the highly contagious nature of measles (relative to diphtheria, pertussis and tetanus) may impart greater amenability to change, following SBM. Third, diagnosis of measles often carries lower ambiguity (owing to distinct rash) relative to diphtheria or pertussis (which commonly present with cough and/or fever), which may correspond with under-diagnosis and under-reporting of the latter.(46-48) This low reporting may have precluded us from detecting the "true" magnitude of cases averted by SBM, even if a true relation between SBM and lower diphtheria, pertussis and tetanus cases actually occurred. However, to the extent that detection remains consistent within a particular district over time, our statistical models render data comparable between time points by utilizing the difference in VPD rates rather than absolute magnitude at each time point.

In 2019, India introduced an indigenously produced rotavirus vaccine into its Universal Immunization Program.(49,50) Rotavirus infections in u5 children account for nearly $40 \%$ of diarrheal episodes in India.(51) Repeated diarrheal infections further exacerbate pre-existing environmental enteropathy, undernutrition and vaccine failure.(4,9) The introduction and expansion of the rotavirus vaccine, in combination with improved sanitation following SBM, may confer substantial benefits to vaccine response and improved nutrition among Indian children. Whereas we do not know of any nationally representative, publicly available data sets that report annual district-level rotavirus surveillance in u5 children, we encourage policy makers to provide this information for future research and evaluation.

Biological markers of environmental enteropathy offer clinically definitive methods to identify the extent and severity of this condition and subsequent evaluation of physiological changes following improved ambient sanitation.(17) Intestinal biopsies conducted in the 1960s, 
such as those by Lindebaum and colleagues., may not serve as feasible means for identification of enteropathy in current epidemiological studies.(22) Recent research identifies malabsorption, changes in local immune activity and intestinal permeability as key diagnostic features of environmental enteropathy.(17) Measurement of biomarkers of carbohydrate malabsorption (e.g., lactulose-mannitol), mucosal activity (e.g., T-helper cell type 1), serum protein from intestinal mucosa and markers of systemic immune activity and inflammation (e.g., C-Reactive Protein, glycoproteins) may provide direct evidence of environmental enteropathy.(17) Such analyses may augment ecological research, such as ours, in understanding clinical as well as epidemiological ramifications of improved sanitation on child health.

\section{Conclusion}

Improvements in ambient sanitation through construction and utilization of toilets may augment current efforts in reducing the burden of Vaccine Preventable Diseases among children in India and other low and middle income countries. 


\section{References}

1. World Health Organization. WHO vaccine-preventable diseases: monitoring system 2020 global summary . WHO vaccine-preventable diseases: monitoring system 2020 global summary. 2020. Available from: https://apps.who.int/immunization_monitoring/globalsummary/timeseries/tsincidencedipht heria.html

2. Ministry of Health and Family Welfare. Universal Immunization Program . Government of India. Available from: https://main.mohfw.gov.in/sites/default/files/5628564789562315.pdf

3. MacLennan CA, Saul A. Vaccines against poverty. Proc Natl Acad Sci U S A . 2014/08/18. 2014 Aug 26;111(34):12307-12. Available from:

https://pubmed.ncbi.nlm.nih.gov/25136089

4. Prendergast AJ. Malnutrition and vaccination in developing countries. Philos Trans R Soc Lond B Biol Sci . 2015 Jun 19;370(1671):20140141. Available from: https://pubmed.ncbi.nlm.nih.gov/25964453

5. Coffey D, Spears D. Where India goes: abandoned toilets, stunted development and the costs of caste. Harper Collins; 2017.

6. World Health Organization. Progress on sanitation and drinking-water 2013 update: Joint Monitoring Programme for Water Supply and Sanitation. 2013; Available from: https://www.who.int/water_sanitation_health/publications/2013/jmp_report/en/

7. Chakrabarti S, Singh P, Bruckner T. Association of Poor Sanitation With Growth Measurements Among Children in India. JAMA Netw Open . 2020 Apr 15;3(4):e202791e202791. Available from: https://doi.org/10.1001/jamanetworkopen.2020.2791

8. Ranzani OT, Tonne C, Barreto ML. Potential for Life Course Health Benefits From Improved Household Environments. JAMA Netw Open . 2020 Apr 15;3(4):e202968e202968. Available from: https://doi.org/10.1001/jamanetworkopen.2020.2968

9. Humphrey JH. Child undernutrition, tropical enteropathy, toilets, and handwashing. Lancet. 2009;374(9694):1032-5.

10. Rytter MJH, Kolte L, Briend A, Friis H, Christensen VB. The immune system in children with malnutrition — a systematic review. PLoS One. 2014;9(8):e105017.

11. Zaman K, Anh DD, Victor JC, Shin S, Yunus M, Dallas MJ, et al. Efficacy of pentavalent rotavirus vaccine against severe rotavirus gastroenteritis in infants in developing countries in Asia: a randomised, double-blind, placebo-controlled trial. Lancet. 2010;376(9741):615-23.

12. Ruiz-Palacios GM, Pérez-Schael I, Velázquez FR, Abate H, Breuer T, Clemens SC, et al. Safety and efficacy of an attenuated vaccine against severe rotavirus gastroenteritis. $\mathrm{N}$ Engl J Med. 2006;354(1):11-22.

13. Maier EA, Weage KJ, Guedes MM, Denson LA, McNeal MM, Bernstein DI, et al. Protein-energy malnutrition alters IgA responses to rotavirus vaccination and infection but 
does not impair vaccine efficacy in mice. Vaccine . 2013;32(1):48-53. Available from: http://www.sciencedirect.com/science/article/pii/S0264410X13014692

14. Haque R, Snider C, Liu Y, Ma JZ, Liu L, Nayak U, et al. Oral polio vaccine response in breast fed infants with malnutrition and diarrhea. Vaccine . 2014;32(4):478-82. Available from: http://www.sciencedirect.com/science/article/pii/S0264410X13015909

15. Zimmermann $\mathrm{P}$, Curtis $\mathrm{N}$. The influence of the intestinal microbiome on vaccine responses. Vaccine . 2018;36(30):4433-9. Available from: http://www.sciencedirect.com/science/article/pii/S0264410X18305632

16. Hoest C, Seidman JC, Pan W, Ambikapathi R, Kang G, Kosek M, et al. Evaluating associations between vaccine response and malnutrition, gut function, and enteric infections in the MAL-ED cohort study: methods and challenges. Clin Infect Dis . 2014 Nov 1;59 Suppl 4(Suppl 4):S273-9. Available from: https://pubmed.ncbi.nlm.nih.gov/25305297

17. Investigators TM-EN. The MAL-ED Study: A Multinational and Multidisciplinary Approach to Understand the Relationship Between Enteric Pathogens, Malnutrition, Gut Physiology, Physical Growth, Cognitive Development, and Immune Responses in Infants and Children Up to 2 Years of . Clin Infect Dis . 2014 Nov 1;59(suppl_4):S193-206. Available from: https://doi.org/10.1093/cid/ciu653

18. Kizito D, Tweyongyere R, Namatovu A, Webb EL, Muhangi L, Lule SA, et al. Factors affecting the infant antibody response to measles immunisation in Entebbe-Uganda. BMC Public Health. 2013;13(1):619.

19. Caulfield LE, de Onis M, Blössner M, Black RE. Undernutrition as an underlying cause of child deaths associated with diarrhea, pneumonia, malaria, and measles. Am J Clin Nutr. 2004;80(1):193-8.

20. Gaayeb L, Pincon C, Cames C, Sarr J-B, Seck M, Schacht A-M, et al. Immune response to Bordetella pertussis is associated with season and undernutrition in Senegalese children. Vaccine. 2014;32(27):3431-7.

21. Korpe PS, Petri WA. Environmental enteropathy: critical implications of a poorly understood condition. Trends Mol Med . 2012;18(6):328-36. Available from: http://www.sciencedirect.com/science/article/pii/S1471491412000706

22. Lindenbaum J, Gerson CD, Kent TH. Recovery of small-intestinal structure and function after residence in the tropics: I. Studies in Peace Corps Volunteers. Ann Intern Med. 1971;74(2):218-22.

23. Swachh Bharat Mission . Department of Drinking Water \& Sanitation, Ministry of Jal Shakti, Government of India. Available from: https://swachhbharatmission.gov.in/sbmcms/index.htm

24. Dalberg WASH Institute. An assessment of the reach and value of IEC activities under Swachh Bharat Mission (Grameen) . 2019. Available from: https://jalshaktiddws.gov.in/sites/default/files/201906_SBM_IEC_Whitepaper.pdf

25. Curtis V. Explaining the outcomes of the "Clean India" campaign: institutional behaviour 
and sanitation transformation in India. BMJ Glob Heal . 2019 Sep 30;4(5):e001892e001892. Available from: https://pubmed.ncbi.nlm.nih.gov/31646010

26. Singh $\mathrm{P}$, Shah M, Bruckner T. Child Undernutrition Following the Introduction of a Large-Scale Toilet Construction Campaign in India. Available SSRN 3471993. 2019;

27. Dandabathula G, Bhardwaj P, Burra M, Rao PVVP, Rao SS. Impact assessment of India's Swachh Bharat Mission - Clean India Campaign on acute diarrheal disease outbreaks: Yes, there is a positive change. J Fam Med Prim care . 2019 Mar;8(3):1202-8. Available from: https://pubmed.ncbi.nlm.nih.gov/31041274

28. Health Management Information System: A digital initiative under National Health Mission . Ministry of Health \& Family Welfare, Government of India. 2020. Available from: https://nrhm-mis.nic.in/hmisreports/frmstandard_reports.aspx

29. Sharma A, Rana SK, Prinja S, Kumar R. Quality of Health Management Information System for Maternal \& Child Health Care in Haryana State, India. PLoS One . 2016 Feb 12;11(2):e0148449. Available from: https://doi.org/10.1371/journal.pone.0148449

30. Dutt R, Sahu M. Temporal Analysis of Infant and Child Health Indicators from Health Management and Information System of a Vulnerable District of India: Tracking the Road toward the Sustainable Development Goal-3. Indian J Community Med . 2019;44(4):3978. Available from: https://pubmed.ncbi.nlm.nih.gov/31802809

31. Health Management Information system: Service Provider's Manual . Ministry of Health \& Family Welfare, Government of India. 2020. Available from: https://nrhmmis.nic.in/SitePages/HMIS-Download.aspx?RootFolder=\%2FPart A HMIS\%2FUnderstanding Health Management Information Systems\&FolderCTID=0x012000AC878C9A74E6DC46A4B9220C1AAC273000235163 07E428FA4F94B5EF39C166F19C\&View=\%7B4DCA3263-12F7-4628-8F36-2D02

32. District Level Household \& Facility Survey (DLHS-4) . Reproductive \& Child Health Project. 2014. Available from: http://rchiips.org/DLHS-4.html

33. Annual Health Survey (AHS) India . Office of the Registrar General and Census Commissioner (India). 2014. Available from:

https://www.censusindia.gov.in/2011 census/hh-series/cab.html

34. International Institute for Population Sciences (IIPS) and ICF. National Family Health Survey (NFHS-4), 2015-16 . Mumbai: IIPS. 2017. Available from: https://dhsprogram.com/pubs/pdf/FR339/FR339.pdf

35. Jung L, De Neve J-W, Chen S, Manne-Goehler J, Jaacks LM, Corsi DJ, et al. Nationally representative household survey data for studying the interaction between district-level development and individual-level socioeconomic gradients of cardiovascular disease risk factors in India. Data Br . 2019 Sep 13;27:104486. Available from:

https://pubmed.ncbi.nlm.nih.gov/31720318

36. Geldsetzer P, Manne-Goehler J, Theilmann M, Davies JI, Awasthi A, Danaei G, et al. Geographic and sociodemographic variation of cardiovascular disease risk in India: A cross-sectional study of 797,540 adults. PLOS Med . 2018 Jun 19;15(6):e1002581. 
Available from: https://doi.org/10.1371/journal.pmed.1002581

37. Dandona R, Pandey A, Dandona L. A review of national health surveys in India. Bull World Health Organ. 2016;94(4):286.

38. UNICEF. The state of the world's children 2008: Child survival . Vol. 8. Unicef; 2007. Available from:

https://www.unicef.org/publications/files/The_State_of_the_Worlds_Children_2008.pdf

39. StataCorp. Stata Statistical Software: Release 14. College Station, TX: StataCorp LP.; 2015.

40. WHO vaccine-preventable diseases: monitoring system. 2020 global summary- India . World Health Organization. 2020. Available from:

https://apps.who.int/immunization_monitoring/globalsummary/countries?countrycriteria\% $5 \mathrm{Bcountry} \% 5 \mathrm{D} \% 5 \mathrm{~B} \% 5 \mathrm{D}=\mathrm{IND} \&$ commit=OK\#

41. Gupta A, Khalid N, Devashish D, Hathi P, Avani K, Srivastav N, et al. Changes in Open Defecation in Rural North India: 2014-2018 . 2019. (IZA Discussion Paper No. 12065). Available from: https://papers.ssrn.com/sol3/papers.cfm?abstract_id=3323179

42. Handley MA, Lyles CR, McCulloch C, Cattamanchi A. Selecting and improving quasiexperimental designs in effectiveness and implementation research. Annu Rev Public Health. 2018;39:5-25.

43. Spears D. Exposure to open defecation can account for the Indian enigma of child height. J Dev Econ. 2018;102277.

44. Jensen KJ, Fisker AB, Andersen A, Sartono E, Yazdanbakhsh M, Aaby P, et al. The effects of vitamin A supplementation with measles vaccine on leucocyte counts and in vitro cytokine production. Br J Nutr . 2015/12/18. 2016;115(4):619-28. Available from: https://www.cambridge.org/core/article/effects-of-vitamin-a-supplementation-withmeasles-vaccine-on-leucocyte-counts-and-in-vitro-cytokineproduction/7FD0E8DB547B140FD2B9844E54FB191A

45. The World Bank. Vitamin A supplementation coverage rate (\% of children ages 6-59 months) - India . United Nations Children's Fund, State of the World's Children. 2020. Available from: https://data.worldbank.org/indicator/SN.ITK.VITA.ZS?locations=IN

46. John TJ, Dandona L, Sharma VP, Kakkar M. Continuing challenge of infectious diseases in India. Lancet . 2011;377(9761):252-69. Available from: http://www.sciencedirect.com/science/article/pii/S0140673610612652

47. Tanu S, Rakesh L, Arti K, Yogesh J, Kabra SK. Diphtheria-down but not out. Indian Pediatr. 2000;37(7):728-38.

48. Forsyth K, von König CHW, Tan T, Plotkin S. Pertussis control in the Asia-Pacific region: a report from the Global Pertussis Initiative. Southeast Asian J Trop Med Public Health. 2012;43(3):699.

49. Malik A, Haldar P, Ray A, Shet A, Kapuria B, Bhadana S, et al. Introducing rotavirus vaccine in the Universal Immunization Programme in India: From evidence to policy to 
implementation. Vaccine . 2019;37(39):5817-24. Available from:

http://www.sciencedirect.com/science/article/pii/S0264410X19310254

50. Ministry of Health and Family Welfare, Government of India. Operational Guidelines: Introduction of Rotavirus Vaccine in Universal Immunization Programme . 2019. Available from:

https://nhm.gov.in/New_Updates_2018/NHM_Components/Immunization/Guildelines_fo r_immunization/Operational_Guidelines_for_Introduction_of_Rotasiil_in_UIP.pdf

51. Parashar UD, Hummelman EG, Bresee JS, Miller MA, Glass RI. Global illness and deaths caused by rotavirus disease in children. Emerg Infect Dis. 2003;9(5):565. 
Table 1: Mean and Standard Deviation (SD) of variables Pre-SBM (in 2013), Post-SBM (in 2016) and change over time (Post SBM minus Pre SBM) across 532 districts (28 states) in India

\begin{tabular}{|l|c|c|c|c|c|}
\hline \multirow{2}{*}{ Variables } & \multicolumn{2}{|c|}{ Pre-SBM (2013) } & \multicolumn{2}{c|}{ Post SBM (2016) } & \multicolumn{2}{c|}{ Change (Post SBM - Pre } \\
SBM)
\end{tabular}


Figure 1: District-level maps of India showing change in diphtheria (Panel A), pertussis (Panel B), tetanus (Panel C) and measles (Panel D), from 2013 to 2016.

Source: India shapefiles were obtained from publicly available GitHub repository: https://github.com/datameet/maps/find/master. Maps in manuscript have been created by authors. 
Figure 2: District-level map of change in percentage of household with toilets in India (2013 to 2016)

Source: India shapefiles were obtained from publicly available GitHub repository:

https://github.com/datameet/maps/find/master. Maps in manuscript have been created by authors. 


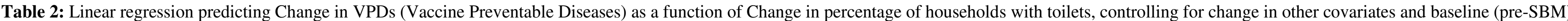
prevalence of VPDs ( $\mathrm{N}=532)$.

\begin{tabular}{|c|c|c|c|c|c|c|c|c|c|c|c|c|}
\hline \multirow{4}{*}{$\begin{array}{l}\text { Covariates } \\
\text { Change in percentage of households with toilets }\end{array}$} & \multirow{2}{*}{\multicolumn{3}{|c|}{$\begin{array}{c}\text { Model } 1 \\
\text { Outcome: change in Diphtheria per } 1000 \\
\text { u5 children }\end{array}$}} & \multirow{2}{*}{\multicolumn{3}{|c|}{$\begin{array}{c}\text { Model } 2 \\
\text { Outcome: change in Pertussis per } 1000 \\
\text { u5 children }\end{array}$}} & \multirow{2}{*}{\multicolumn{3}{|c|}{$\begin{array}{c}\text { Model } \mathbf{3} \\
\text { Outcome: change in Tetanus per } 1000 \\
\text { u5 children }\end{array}$}} & \multirow{2}{*}{\multicolumn{3}{|c|}{$\begin{array}{c}\text { Model } \mathbf{4} \\
\text { Outcome: change in Measles per } 1000 \\
\text { u5 children }\end{array}$}} \\
\hline & & & & & & & & & & & & \\
\hline & \multirow{2}{*}{$\begin{array}{c}\text { Coefficient } \\
0.006\end{array}$} & \multicolumn{2}{|c|}{$95 \% \mathrm{CI}$} & \multirow{2}{*}{$\begin{array}{c}\text { Coefficient } \\
-0.007 \\
\end{array}$} & \multicolumn{2}{|c|}{$95 \% \mathrm{CI}$} & \multirow{2}{*}{$\begin{array}{c}\text { Coefficient } \\
-0.000 \\
\end{array}$} & \multicolumn{2}{|c|}{$95 \% \mathrm{CI}$} & \multirow{2}{*}{$\begin{array}{c}\text { Coefficient } \\
\mathbf{- 0 . 3 2 8} * \\
\end{array}$} & \multicolumn{2}{|c|}{$95 \% \mathrm{CI}$} \\
\hline & & {$[-0.026$} & $0.039]$ & & {$[-0.020$} & $0.006]$ & & {$[-0.021$} & $0.020]$ & & {$[-0.641$} & $-0.014]$ \\
\hline Change in percentage of households with electricity & 0.009 & {$[-0.014$} & $0.033]$ & -0.006 & {$[-0.014$} & $0.001]$ & -0.001 & {$[-0.010$} & $0.007]$ & 0.144 & {$[-0.013$} & $0.302]$ \\
\hline $\begin{array}{l}\text { Change in percentage of households with clean } \\
\text { drinking water }\end{array}$ & -0.011 & {$[-0.030$} & $0.008]$ & 0.003 & {$[-0.012$} & $0.018]$ & -0.009 & {$[-0.021$} & $0.004]$ & -0.161 & {$[-0.389$} & $0.066]$ \\
\hline $\begin{array}{l}\text { Change in percentage of households with clean } \\
\text { cooking fuel }\end{array}$ & 0.013 & {$[-0.009$} & $0.034]$ & 0.005 & {$[-0.006$} & $0.017]$ & -0.011 & {$[-0.025$} & $0.002]$ & -0.127 & {$[-0.369$} & $0.114]$ \\
\hline $\begin{array}{l}\text { Change in percentage of women with } 10^{\text {th }} \text { grade or } \\
\text { higher education }\end{array}$ & 0.012 & {$[-0.023$} & $0.046]$ & 0.015 & {$[-0.014$} & 0.043] & 0.010 & {$[-0.006$} & $0.026]$ & 0.432 & {$[-0.078$} & $0.941]$ \\
\hline $\begin{array}{l}\text { Change in percentage of } \leq 1 \text { year old children with } \\
\text { DPT vaccination }\end{array}$ & -0.004 & {$[-0.024$} & $0.015]$ & 0.004 & {$[-0.002$} & $0.010]$ & -0.015 & {$[-0.035$} & $0.005]$ & -- & -- & -- \\
\hline $\begin{array}{l}\text { Change in percentage of } \leq 1 \text { year old children with } \\
\text { measles vaccination }\end{array}$ & -- & -- & -- & -- & -- & -- & -- & -- & -- & -0.128 & {$[-0.326$} & $0.070]$ \\
\hline Change in percentage of births in hospitals & 0.005 & {$[-0.022$} & $0.031]$ & -0.011 & {$[-0.024$} & $0.002]$ & 0.008 & {$[-0.015$} & $0.032]$ & 0.166 & {$[-0.115$} & $0.447]$ \\
\hline Baseline (pre-SBM) Diphtheria per 1000 u5 children & $-0.997 * * *$ & {$[-1.020$} & $-0.975]$ & -- & -- & -- & -- & -- & -- & -- & -- & -- \\
\hline Baseline (pre-SBM) Pertussis per 1000 u 5 children & -- & -- & -- & $-0.999 * * *$ & {$[-1.003$} & $-0.996]$ & -- & -- & -- & -- & -- & -- \\
\hline Baseline (pre-SBM) Tetanus per 1000 u5 children & -- & -- & -- & -- & -- & -- & $-1.001 * * *$ & {$[-1.006$} & $-0.996]$ & -- & -- & -- \\
\hline Baseline (pre-SBM) Measles per 1000 u5 children & -- & -- & -- & -- & -- & -- & -- & -- & -- & $-0.767 * * *$ & {$[-0.897$} & $\begin{array}{l}-0.638] \\
\end{array}$ \\
\hline
\end{tabular}

$* \mathrm{p}<0.05, * * \mathrm{p}<0.01, * * * \mathrm{p}<0.001$ 


\section{Appendix}

Appendix Table A.1: Distribution of mean of change in VPDs (Diphtheria, Pertussis, Tetanus, Measles) per 1000 u 5 children by 5-unit increments of their respective percentile distributions (532 districts in India, change estimated as the difference between year 2016 and year 2013 values)

\begin{tabular}{|c|c|c|c|c|}
\hline Percentile & Diphtheria & Pertussis & Tetanus & Measles \\
\hline $1^{\text {st }}$ & -42.6 & -25.5 & -12.6 & -165.8 \\
\hline $5^{\text {th }}$ & -6.6 & -3.1 & -2.2 & -65.3 \\
\hline $10^{\text {th }}$ & -2.3 & -0.8 & -0.5 & -33.2 \\
\hline $25^{\text {th }}$ & 0 & 0 & 0 & -13.6 \\
\hline $50^{\text {th }}$ & 0 & 0 & 0 & -0.1 \\
\hline $75^{\text {th }}$ & 0 & 0 & 0 & 4.5 \\
\hline $90^{\text {th }}$ & 0 & 0 & 0 & 20.8 \\
\hline $95^{\text {th }}$ & 1.1 & 0 & 0.1 & 43.9 \\
\hline $99^{\text {th }}$ & 14.4 & 3.1 & 5.3 & 135 \\
\hline
\end{tabular}




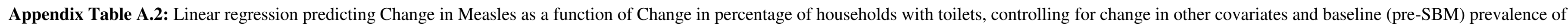
measles, by 6 administrative regions of India.

\begin{tabular}{|c|c|c|c|c|c|c|c|c|c|c|c|c|c|}
\hline \multirow{3}{*}{$\begin{array}{l}\text { Covariates } \\
\\
\begin{array}{l}\text { Change in percentage of } \\
\text { households with toilets }\end{array}\end{array}$} & \multicolumn{2}{|c|}{ Central } & \multicolumn{2}{|c|}{ Eastern } & \multicolumn{2}{|c|}{ North Eastern } & \multicolumn{2}{|c|}{ Northern } & \multicolumn{2}{|c|}{ Southern } & \multicolumn{3}{|c|}{ Western } \\
\hline & Coefficient & $95 \% \mathrm{CI}$ & Coefficient & $95 \% \mathrm{CI}$ & Coefficient & $95 \% \mathrm{CI}$ & Coefficient & $95 \% \mathrm{CI}$ & Coefficient & $95 \% \mathrm{CI}$ & Coefficient & \multicolumn{2}{|c|}{$95 \% \mathrm{CI}$} \\
\hline & $-1.223^{*}$ & {$\left[\begin{array}{ll}-2.390 & -0.057]\end{array}\right.$} & 0.006 & $\left.\begin{array}{ll}-0.503 & 0.515\end{array}\right]$ & $-0.475^{*}$ & {$\left[\begin{array}{ll}-0.882 & -0.068\end{array}\right]$} & 0.331 & {$\left[\begin{array}{ll}-0.226 & 0.887]\end{array}\right.$} & -0.317 & {$\left[\begin{array}{ll}-0.992 & 0.357\end{array}\right]$} & 0.202 & {$[-0.544$} & $0.949]$ \\
\hline $\begin{array}{l}\text { Change in percentage of } \\
\text { households with electricity }\end{array}$ & 0.526 & {$\left[\begin{array}{ll}-0.067 & 1.119]\end{array}\right.$} & $-0.300^{*}$ & {$\left[\begin{array}{ll}-0.572 & -0.029\end{array}\right]$} & -0.032 & $\left.\begin{array}{ll}-0.452 & 0.388\end{array}\right]$ & -0.150 & {$\left[\begin{array}{ll}-0.617 & 0.317]\end{array}\right.$} & 0.612 & {$\left[\begin{array}{ll}-1.432 & 2.656\end{array}\right.$} & -0.268 & {$[-2.041$} & $1.505]$ \\
\hline $\begin{array}{l}\text { Change in percentage of } \\
\text { households with clean drinking } \\
\text { water }\end{array}$ & -0.428 & {$\left[\begin{array}{ll}-2.107 & 1.250]\end{array}\right.$} & 0.381 & {$\left[\begin{array}{ll}-0.122 & 0.884]\end{array}\right.$} & 0.275 & {$[-0.401$} & -0.270 & {$\left[\begin{array}{ll}-0.812 & 0.271]\end{array}\right.$} & -0.095 & {$\left[\begin{array}{ll}-0.415 & 0.224\end{array}\right]$} & -0.636 & {$[-1.352$} & $0.081]$ \\
\hline $\begin{array}{l}\text { Change in percentage of } \\
\text { households with clean cooking fuel }\end{array}$ & 0.545 & $\begin{array}{ll}-0.303 & 1.393]\end{array}$ & $-1.094 *$ & {$\left[\begin{array}{ll}-2.042 & -0.146\end{array}\right]$} & -0.216 & $\left.\begin{array}{ll}-0.892 & 0.459\end{array}\right]$ & -0.113 & {$\left[\begin{array}{ll}-0.469 & 0.242]\end{array}\right.$} & -0.220 & {$\left[\begin{array}{ll}-0.492 & 0.052\end{array}\right]$} & -0.162 & {$[-0.735$} & $0.410]$ \\
\hline $\begin{array}{l}\text { Change in percentage of women } \\
\text { with } 10^{\text {th }} \text { grade or higher education }\end{array}$ & $3.006^{* *}$ & {$\left[\begin{array}{ll}0.762 & 5.250\end{array}\right]$} & 1.834 & {$[-0.657$} & -0.252 & {$[-1.100$} & -0.127 & {$\left[\begin{array}{ll}-1.143 & 0.889\end{array}\right]$} & -0.329 & {$\left[\begin{array}{ll}-0.818 & 0.160\end{array}\right]$} & 0.732 & {$[-0.226$} & 1.690] \\
\hline $\begin{array}{l}\text { Change in percentage of } \leq 1 \text { year } \\
\text { old children with measles } \\
\text { vaccination }\end{array}$ & -0.233 & {$[-1.039$} & 0.238 & {$[-0.363$} & -0.223 & {$[-0.523$} & -0.131 & {$[-0.439$} & $0.311^{*}$ & {$\left[\begin{array}{ll}0.012 & 0.610\end{array}\right]$} & -0.350 & {$[-1.409$} & 0.709] \\
\hline $\begin{array}{l}\text { Change in percentage of births in } \\
\text { hospitals }\end{array}$ & -0.087 & $\left.\begin{array}{lll}-0.740 & 0.565\end{array}\right]$ & $0.814^{*}$ & $1.595]$ & 0.205 & {$[-0.239$} & -0.312 & {$[-0.929$} & 0.264 & {$[-0.479$} & 0.254 & {$[-0.936$} & $1.444]$ \\
\hline $\begin{array}{l}\text { Baseline (pre-SBM) Measles per } \\
1000 \text { u } 5 \text { children }\end{array}$ & $-0.967 * * *$ & {$\left[\begin{array}{ll}-1.156 & -0.778\end{array}\right]$} & $-0.798 * * *$ & {$\left[\begin{array}{ll}-0.910 & -0.685\end{array}\right]$} & -0.291 & {$[-0.629$} & -0.449 & {$\left[\begin{array}{ll}-1.145 & 0.247]\end{array}\right.$} & $-0.736 * * *$ & {$[-0.975 \quad-0.496]$} & $-0.810^{* * * *}$ & {$[-1.161$} & $-0.459]$ \\
\hline $\mathrm{N}$ & & 121 & & 107 & & 80 & & 85 & & 103 & & 36 & \\
\hline
\end{tabular}

${ }^{*} \mathrm{p}<0.05, * * \mathrm{p}<0.01, * * * \mathrm{p}<0.001$ 
Appendix Table A.3: Mean of change in (1) measles per 1000 u5 children and (2) percentage of households with toilets, by India's administrative regions.

\begin{tabular}{|l|c|c|}
\hline Region & $\begin{array}{l}\text { Mean change in measles per 1000 } \\
\text { u5 children }\end{array}$ & $\begin{array}{l}\text { Mean change in \%age of households } \\
\text { with toilets }\end{array}$ \\
\hline central & -7.44 & 7.97 \\
\hline eastern & -14.68 & 5.50 \\
\hline north eastern & -0.60 & 9.93 \\
\hline northern & -0.96 & 7.76 \\
\hline southern & -3.91 & 4.23 \\
\hline western & 5.80 & 0.57 \\
\hline
\end{tabular}

Appendix Figure A.1: Average marginal effect (with 95\% Confidence Intervals) of change in percentage of household with toilets on counts of u5 measles cases per district in India

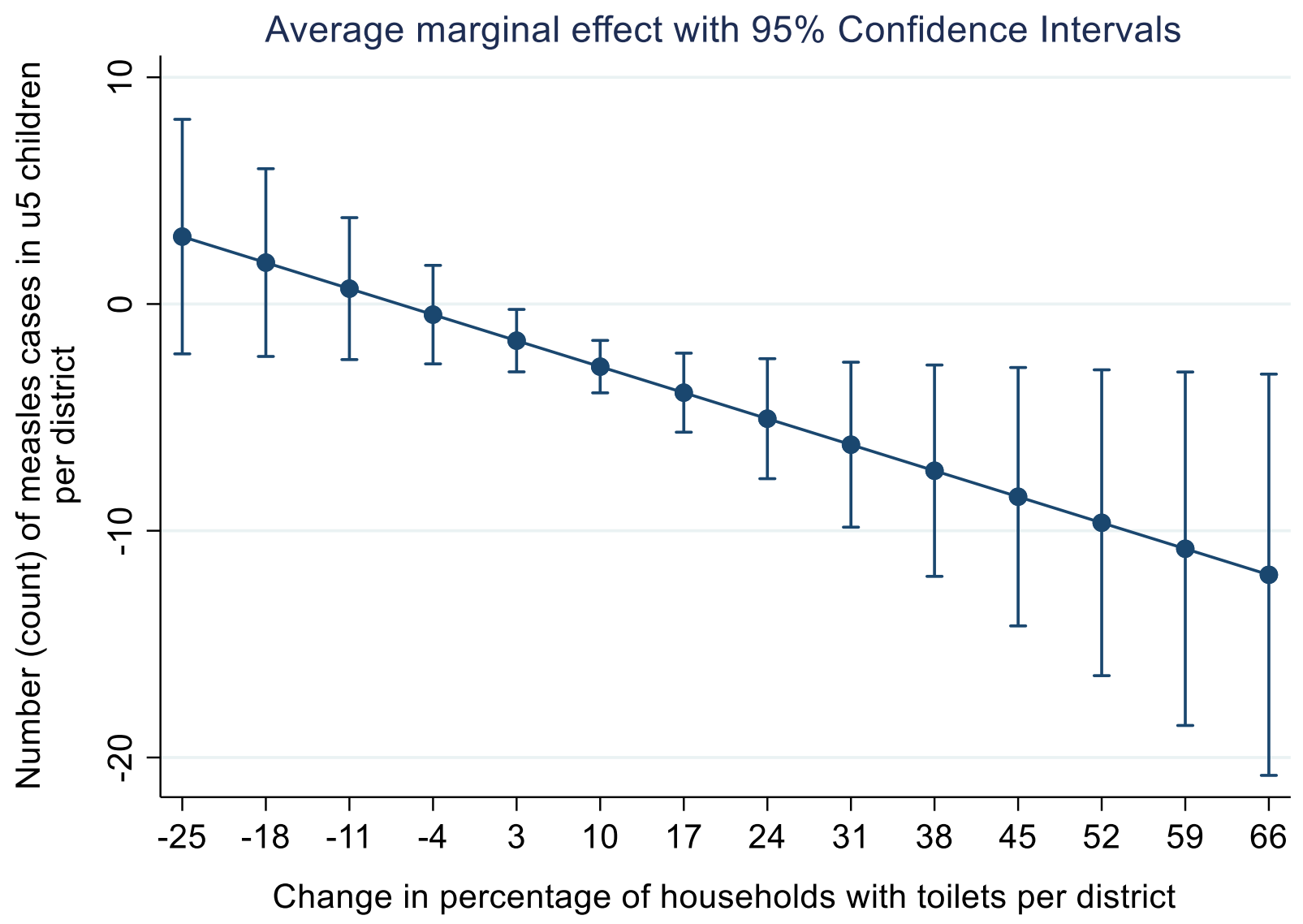


Figures

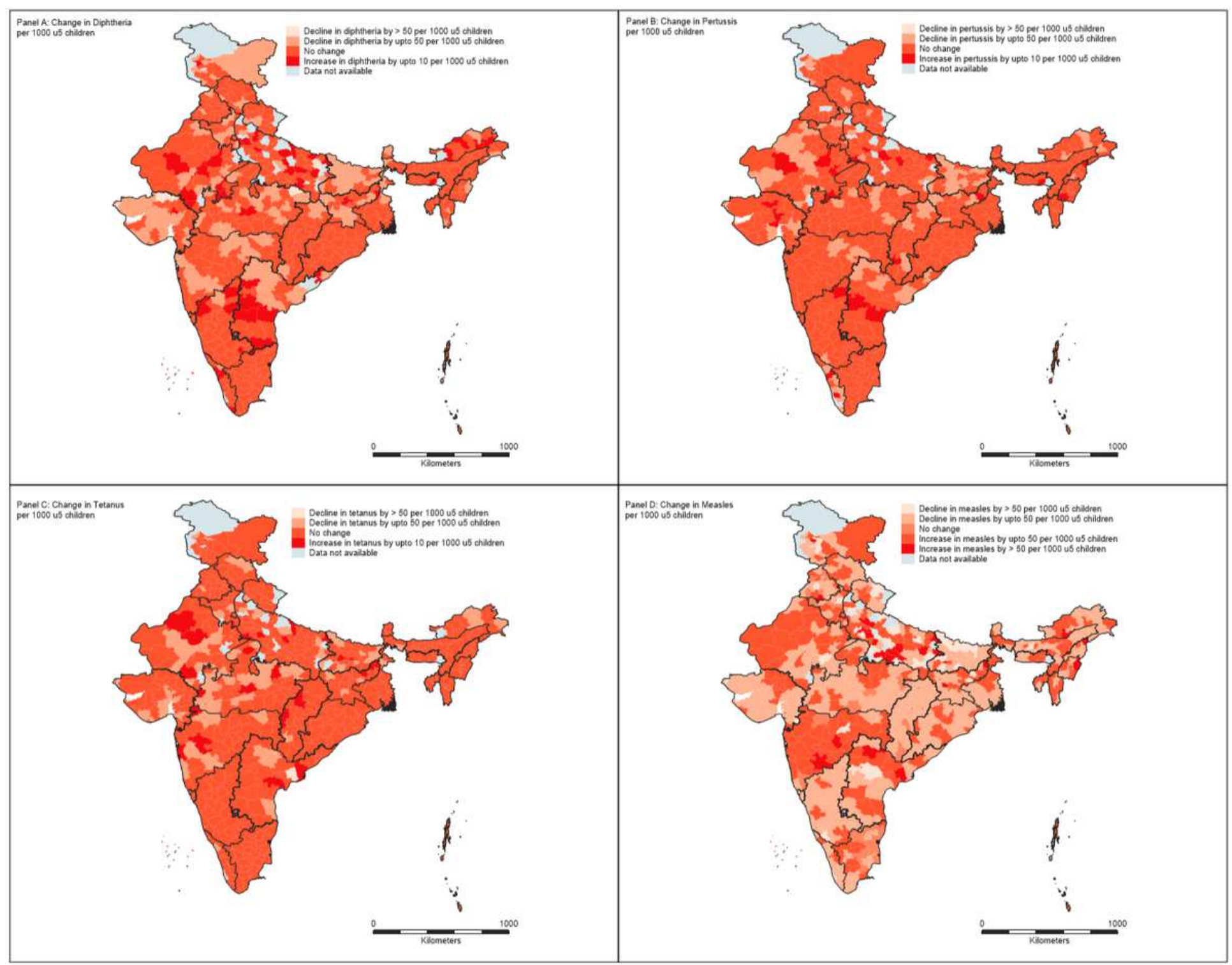

Figure 1

District-level maps of India showing change in diphtheria (Panel A), pertussis (Panel B), tetanus (Panel C) and measles (Panel D), from 2013 to 2016. Source: India shapefiles were obtained from publicly available GitHub repository: https://github.com/datameet/maps/find/master. Maps in manuscript have been created by authors. 


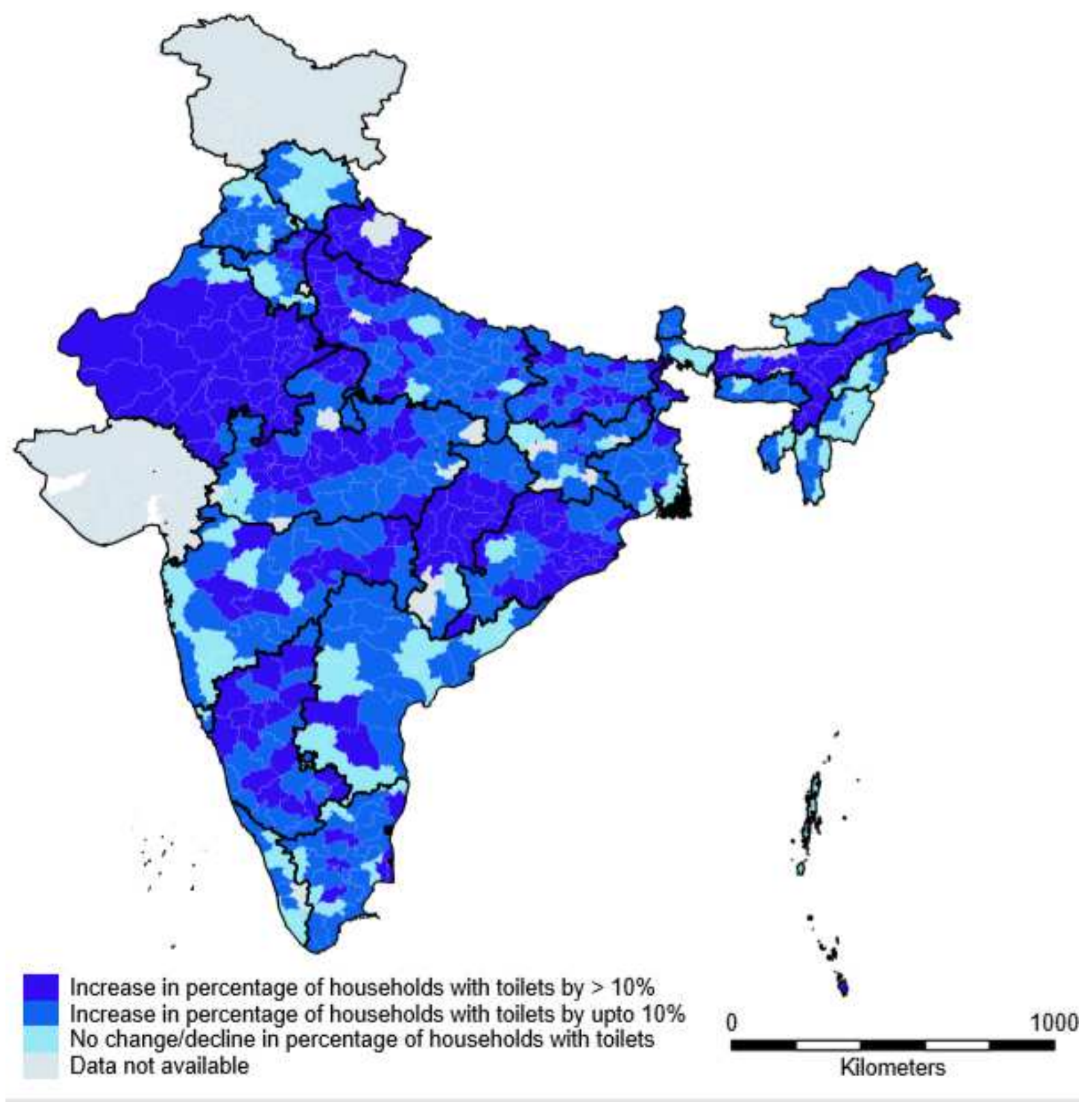

Figure 2

District-level map of change in percentage of household with toilets in India (2013 to 2016) Source: India shapefiles were obtained from publicly available GitHub repository:

https://github.com/datameet/maps/find/master. Maps in manuscript have been created by authors.

\section{Supplementary Files}

This is a list of supplementary files associated with this preprint. Click to download.

- SupplementarymaterialAppendix.docx 